\title{
Dressed bodies and built environments: the interactive composition of public space
}

\section{Clemens Thornquist}

University of Borås, The Swedish School of Textiles, Sweden

clemens.thornquist@hb.se

\begin{abstract}
The human body has been pivotal in much architectural research. Researchers of public space often underscore its interactive and transformative qualities as linking to a broader understanding of the different individual social practices taking place in such spaces. What seems to be lacking however is an analysis of the relationship between the dressed body and the built environment which together constitute a public space. The aim of this paper is to explore and elaborate on the interaction between dressed bodies and architectural structures and outline an alternative approach to understanding the different aesthetic forces at play in the constitution of public space. Using a photographic series of piloted experimental sites, this paper points out how the aesthetics of fashion enrich, contribute to, and change the aesthetics of urban architectural environments. The result prompts a clearer understanding of the interaction between dressed bodies and architecture and offers guidance for future research designed to bridge the gap between the aesthetics of the scale of the body and the scale of building and infrastructure in the constitution of public space.
\end{abstract}

Keywords: fashion, architecture, public space, environmental composition, urban design

To cite this article:

Thornquist, C. (2019). Dressed bodies and built environments: the interactive composition of public space. The Journal of Public Space, 4(I), 3-I4, DOI I0.3289I/jps.v4il.662

This article has been double blind peer reviewed and accepted for publication in The Journal of Public Space.

This work is licensed under a Creative Commons Attribution - Non Commercial 4.0 International License https://creativecommons.org/licenses/by-nc/4.0/ 


\section{Fashion and architecture: some common-ground notions}

Dress and shelter are fundamental to social life. While conditions in the physical world frequently force us to put on clothes and shelter in dwellings, the social world only asks that we be dressed and live in houses. Dress, as Entwistle (2000) notes, not only protects our modesty and reflects a natural body or a given identity, it also enhances that body and through the materials used adds a diversity of meaning to it that would otherwise not be there. As such, dress negotiates the tension between the human desire to stand out and be different and the equally human desire to fit in and be accepted (Simmel, 19l1). Similar needs and desires are also consequential in architectural design. The need to feel at home and be "camouflaged" within the environment, to fit in and be accepted, is central to architectural constructions. In addition, in the exercise of fashion, this process of assimilation is not merely a physical operation. Dressing in clothing requires us to assimilate on a mental level, to think ourselves into the environment (Leach, 2006). Similarly urban space and urban cities have also been recognised as the self-awareness of inhabitants' psychological, social, and economical production (Lefebvre, 199I). In his documentary film Notebook on Cities and Clothes, Wenders (1989) elaborates:

Identity ... of a person, of a thing, of a place. Identity. The word itself gives me shivers. It rings of calm, comfort, contentedness. What is it, identity? To know where you belong? To know your self worth? To know who you are? How do you recognize identity? We are creating an image of ourselves. We are attempting to resemble this image... Is that what we call identity? Between the image we have created of ourselves and ... ourselves? Just who is that, 'ourselves' ? ... We live in the cities. The cities live in us. Time passes.

Fashion and architecture do not only express ideas of personal, social, and cultural identity and reveal a person's aesthetic pleasures or narcissistic self-absorption; dress and built environments also reflect similar interests of the targeted audience and clients. Perhaps this is particularly true for consumers and clients who celebrate the fluid play with signs and simulacra in dress and in architecture that works to dissolve the connection between political economies and the real (Baudrillard, 1983; 1998) and where fashion consumption is increasingly more integrated in the shaping of contemporary architecture and its public spaces (Koolhaas et al. 2002).

Architecture, like fashion, has also been affected by the contemporary idea that current westernised societies are identifiable by the individual rather than the collective, an idea of individualism that is marked not only by neoliberal nationalism and capitalism that urge ownership of property - or clothing - and the freedom of choice, but also the laying of claims to the particular and the authentic (Rajagopalan, 20I2). Thus originality, authenticity, and differentiation, in the sense of the present-day individual and her ambitions are not only tied to dress but to buildings and cities and the object at large. As Benjamin points out, "Fashion, like architecture, inheres in the darkness of the lived moment and belongs to the dream consciousness of the collective" (Benjamin, 2002: 393). The relationship between fashion and architecture is also further expressed in both diciplines - at times similar and at other times twisted-they lie between history 
and the present, those in power and those under it and between the culturally sophisticated and the naïve. In Benjamin's (2007: 26I) words:

Fashion has a flair for the topical, no matter where it stirs in the thickets of long ago; it is a tiger's leap into the past. This jump, however, takes place in an arena where the ruling class gives the commands. The same leap in the open air of history is the dialectical one, which is how Marx understood the revolution.

Sabatino, for example, has demonstrated in a series of cases that the issues of what he calls the primitive or savage "exemplify a diffused phenomenon that has engendered the competing politics of modern identity that in turn have shaped nineteenth- and twentieth-century architecture and urbanism" (Sabatino, 2008:362). On a similar note, Morton (2000) has commented that even where world expositions have aimed to separate the 'native' from colonialism - for example where one "demonstrated Europe's sophistication in art deco style, while the colonial pavilions were 'authentic' native environments for displaying indigenous peoples and artifacts from the colonies,"- the two are instead often mixtures of both. These problematic issues are also seen in fashion (Rovine, 2009), where the matter is complicated further still, by the notion that what constitutes "a dress" or a "liveable house" may vary within a particular culture and from culture to culture; what is an appropriate house or legal or illegal dress also varies from situation to situation as well as from nation to nation.

More particularly, the competition or struggle between the savage and the cultivated, between the historic and the contemporary, between the colonised and the coloniser have also been manifested in three realms applicable to both architecture and fashion: (I) in the dialogue between culturally-developed styles and more archaic typologies, (2) in the desire to restore nature to the city or in clothing, or to exit the city or fashion in search of rural environments and elemental clothing, and (3) in the desire to integrate the tectonics and technologies of vernacular architecture and fashion with contemporary construction practices of buildings and clothing (Sabatino, 2008; Loppa, 2003). In more pragmatic terms, perhaps, and regardless of moral and ethical considerations, relatable approaches of both architecture and fashion to materials engineering and new technologies have raised questions about the interdisciplinary nature of contemporary design. Here the architects' "fearless adoption of new design technologies and the resultant construction methods" have for example been compared with the fashion designers' "struggle for liberation from convention" to shape and redefine the appearance of the female body (Hodge et al., 2006: II). Fashion and architecture do however not only share similar socio-functional aims and challenges; each of them also competes and challenges one another in the process of constituting urban environments and public spaces through its constructed elements. As Reinhardt (2007: 182) observes, "both clothing fashion and architecture produce surfaces that convey a cultural message relating to occupation, program, status, or individual profile." They operate on several different levels beyond personalised configuration for habitation and protection from direct exposure to disturbing influences (Barnard 2002) or establishment of a private and secure zone within a determined boundary (Semper, 1989). As clothing constructions and built environments are three-dimensional spatial geometries that together establish most of our everyday spaces, places, and situations, architectural constructions cannot be understood without 
considering their relationship to the dressed body. Similarly, while the dressed body is most often situated in a constructed environment, it cannot be fully understood without reference to its built environment. Researchers have explored the relationship between the body and buildings (e.g. Dodds and Tavenor, 2002); what is lacking is an analysis of the relationship between fashion as the dressed body and architecture as the built environment from the perspective of how together they establish the dynamic aesthetics of urban environments, public spaces, and infrastructure.

In this paper I will adopt a first-person perspective to present a proposal for a methodology that attempts to artistically analyse the co-created aesthetic impact that the interaction between dressed bodies and buildings has on public spaces. A central reason for developing such a method is to find paths to in-depth artistic analyses that can bridge the gap between fashion theories that leave out the built environment and architectural theories that leave out the dressed bodies in the process of aesthetically co-producing public spaces, urban environments, and interior places.

\section{Co-creation of public space through the interaction between dressed bodies and built structures}

A public space has been described as the stage upon which the drama of communal life unfolds and as a place that provides channels for movement, nodes of communication, and common ground for play and relaxation. As such, a public space in its being a human-made environment may be said to "afford[s] casual encounters in the course of daily life that can bind people together and give their lives meaning and power" (Carr et al., 1992:45). In line with this thinking around constructed public space, Carr et al. suggest how to best design such spaces, using a framework where three critical human dimensions would guide the process of designing public spaces: the users' essential needs, their spatial rights, and the meanings they seek.

In architecture, this approach may be related to the conventional idea that the built environment is not immediately responsive to change. Reinhardt (2007) explains that while various spatial, material, or structural alternatives may be explored in the design phase, during construction a selection results in the artificially constructed space becoming a constant. If variation is inscribed into the constructed space, it may still all too often induce conformity because it generally allows for only a series of predetermined alternatives through structures or environments that accommodate multiple functions at the same time, sequentially, or at periodically recurring events (Preiser et al. 2017) rather than being responsive to unforeseen contingencies. If the built environment is instead to be flexible, adaptable, and a responsive space, Reinhardt (2007:182) argues, these options must be embedded into the architectural spatial system, both in the design process and in the built space itself: "strategies of compression, intensity, or elasticity might therefore enable a dynamic spatial capacityin response and interaction - not exclusively through a physical operation, but through phenomenal or interpretative shifts."

One such shift in perspective is presented by Grosz (200I), who contends that change and emergence, traditionally viewed as outside the concerns of space, must become more integral to the processes of design and construction. For example, an issue that surfaces in the consideration of the fabrication of bodies through dress is the case against architecture's historical indifference to sexual specificity: what does the 
existence of at least two sexes have to do with how we understand and experience space? In fashion, the contrary has been argued. Lipovetsky (1994: 149), for example, concludes in her analysis of fashion and change that today's fashion economy has created a social agent in its own image: "the fashion person who has no deep attachments, a mobile individual with a fluctuating personality and tastes" with such openness to change that it "requires a rethinking of the classic charges brought against frivolous society, accusing it of organized waste and bureaucratic-capitalist irrationality." The result, she argues, is a new type of kinetic, open personality fundamental to societies in rapid transformation and constituted through fluctuations in dress. While designers of public spaces on the one hand may be guided by frameworks similar to the one suggested by Carr et al. (1992) — the users' essential needs, their spatial rights, and the meanings they seek - other research related to the functional and expressional aesthetics of the interactions between body and space recognise the vague dynamics and ambiguous meanings that are not only attributed to public spaces but also emerge from them (Kenniff, 2018). Lefebvre (1991: 26) expresses it this way:

(Social) space is a (social) product [...] the space thus produced also serves as a tool of thought and of action; that in addition to being a means of production it is also a means of control, and hence of domination, of power; yet that, as such, it escapes in part from those who would make use of it.

For Lefebvre. then, the street is a central space for understanding innovative social practices; it transforms the spatial-temporal form of the space itself into something that it was not before (Lefebvre, 2003). From this perspective, often influenced by the revival of the 1980s' material-semiotic method of actor-network-theory (e.g. Latour 2005), human and non-human aspects are considered to have reciprocity and shared agency in the co-construction of socio-material assemblages. As Farías (2009:14) maintains:

The notion of urban assemblages in the plural form provides an adequate conceptual tool to grasp the city as a multiple object, to convey a sense of its multiple enactments. There are many reasons for using this notion. Firstly, it is a term that provides a concrete and graspable image of how the city is brought into being and made present in ensembles of heterogeneous actors, material and social aspects. This idea of a sociomaterial and socio-technical ensemble is the most literal meaning of assemblage.

From this more dynamic perspective, strategies for giving form to and constructing urban environments are also guided by notions such as those Gehl (2010) has presented: lively, safe, sustainable, and healthy. In his argument for the lively space, however, Gehl goes further and argues that constructed urban landscapes must also be considered through all the human senses, a more concrete, or abstract, aesthetic approach. However, while these different approaches emphasise the more interactive and transformative qualities of public space in different ways, they still consider individuals from the perspective of habitation, dwelling, or carrying out different activities such as walking or moving in the given space. Still overlooked is how dressed bodies in their interaction with built environments challenge and co-construct public spaces - habitat and occupational patterns - and how this mutual interaction may give 
rise to volatile and unexpected spaces through its relationship with the built environment.

\section{Method}

In the shift from the understanding of the aesthetics of space as something emerging from the interaction between dressed bodies and constructed environments and from space as a socio-material construction to space as more of an abstracted aesthetical composition, Leibniz's (2006) notion of space as an unconventional a-priori may be useful. In this kind of space - in which both space and time are not considered real entities but virtual relationships-space is a process that develops through the structuring of matter as a result of the relationship between objects, a view that corresponds to the hypothesis that dressed bodies co-create the aesthetics of public space in their interaction with the built environment. As unconventional a-priori, such space is also not the sum of ideal spatial relations but prior to its parts and divisions. In other words, spaces co-created by dressed bodies and built constructions (may) give rise to new spatial typologies. In Leibniz (2000:47) words:

I observe, that the traces of moveable bodies, which they leave sometimes upon the immoveable ones on which they are moved; have given men occasion to form in their imagination such an idea, as if some trace did still remain, even when there is nothing unmoved. But this is a mere ideal thing, and imports only, that if there was any unmoved thing there, the trace might be marked out upon it. And it is this analogy, which makes men fancy places, traces and spaces; though those things consist only in the truth of relations, and not at all in any absolute reality.

For Leibniz, according to Evangelidis (2018: 3), this suggests that spatial and temporal relationships between objects and events are immediate and not reducible to spacetime point relations, and all movement is the relational movement of bodies. As such, space is infinitely divisible and space is an order of potentialities - in this case aesthetic potentialities.

Moving from understanding the aesthetics of clothes and buildings in a more representative way to the aesthetics of spaces as a dynamic expression emerging from the interaction between dressed bodies and dressed spaces also means that the traditional 'context plus object gives meaning' is disturbed. Hegel (1949) notes that to use a method that methodologically positions the result in a historical sketch or to trace the process of how it came to light is perhaps of interest but is of no significance to the expounding of philosophical truth, or in this case, is of no significance to judging the aesthetic effect of dressed bodies and dressed space on the construction of social spaces. Instead of forming a context that adds rigor to the understanding of particularities by looking at it from different perspectives, a universality may be evaluated from the other direction: the expressed potential of the proposition expressed through the art model that is established through a repetition of cases different in degree (Deleuze 2004). As a consequence, while theory in many embodied analyses appears in text, theory by context through text is here replaced by theory through self-institutional and self-referential visual/ material systems (Versluis and Uyttenbroek, 20l4); each case is both an exercise and outcome of an inquiry (Wood et 
al. 20I I). For this reason, the proposed method builds on the photographic work of Hilla and Bernd Becher (Lange, 2006), where single images are grouped in grids where each image reflects the others from different perspectives. From this standpoint, the significance of Becher's work is here lies not so much in the content of the work itself but in its normative and self-instituting epistemological structure. The method may be described as photographic clustering, or as Stimson (2004) drawing on Foucault argues, an epistemology and a system of dispersion that is "neither a configuration, nor a form" but instead a process or "a group of rules that are immanent in a practice" (Foucault, 1976: 37, 46).

The focus of this photographic method, or the type of methodology that this method suggests, is firstly an expressional opportunity and a challenge to the way spaces are established aesthetically at a foundational level before any more precise and particular theoretical meaning-making occurs. The method aims to be sensitive and open to the diversity of meanings and expressions that are generated on a more sublime level. For example, while a fashion brand may give rise to more framed connotations or designs in architecture may utilise a clearer semiotic structure, the multitude of expression in the interaction of simple dressed bodies and 'dressed spaces' is much more complex and open to meanings, and meanings tend to emerge more from the process of interaction (Wiberg, 2018; Baudrillard, 2002). Through employing the method I will also propose some of the connections that can be made between the various theorists in these related areas on a fundamental aesthetic level, suggesting how one might make a study of public space and urban environments through photography. In doing so, I will also outline a theoretical perspective that takes as its starting point the idea that public space and urban environments are co-constructed and that dressed bodies are fundamental in constituting social order.

\section{Results \& Discussions}

The following settings present the pre-study and pilot of this method. The investigation is based on three different spaces with three different aesthetics in relation to form and material in the dressed bodies and the built constructions. While it is common to consider public spaces as non-profit, non-commercial, places for social gathering like squares and parks (e.g. Carr et al. 1992), I will in this pilot study also include semi-public sites of consumption such as hotels, museums, streets, and other spaces. This choice is based on the argument that consumption has become integral in the formation of architecture (Koolhaas et al., 2002) and the formation of social urban gathering places (Zukin, 1995), and in ways similar to non-commercial places, allows people to interact and gather in social congregation apart from the home (Oldenburg, I991, Lofland, 1998). Much as Humphreys (20I0) and Zukin (1995) have, I will look at cases of public spaces in the broader sense of "non-domestic physical sites that are distinguished by their relative accessibility" (Humphreys, 2010: 764), those that more accurately reflect the everyday practice of urban life. The settings for the pilot test are: A, fig. I-8 an arcade; B, fig. 9-16, a street; C, fig. 17-24, a church; D, fig. 25-32, a museum. In the first print, A, which could be described as a semi-open and more sublime form of arcade, the inclusion of dressed bodies appears to have a direct effect that almost appears to grow gradually, or even exponentially, with the expressions of the dress as well as the sheer volume of bodies. On the other hand, a rather subtle introduction of a 
pink color in traditional form has already had a strong impact in that a single body works to shift the entire dynamics of the space, something that does not occur in the same way with multiple bodies dressed in more traditional formal wear in black, white, and blue. This is contrasted in setting $D$, where the number and type of expression of the dressed bodies in relation to the room is more constant, where the strong black graphic postures and the internal relationship between the two dressed graphic bodies are significant for their overall impact on the perceived space. In instances, the built structure and dressed bodies together seem even to amplify each other into an all-new dynamic. In example $B$, the street, which is marked by a strong sensory and material presence of a building material (colour) and pavement material (texture), the dressed bodies appear to be more marginalised, conditioned by the frame of the wall and the pavement.
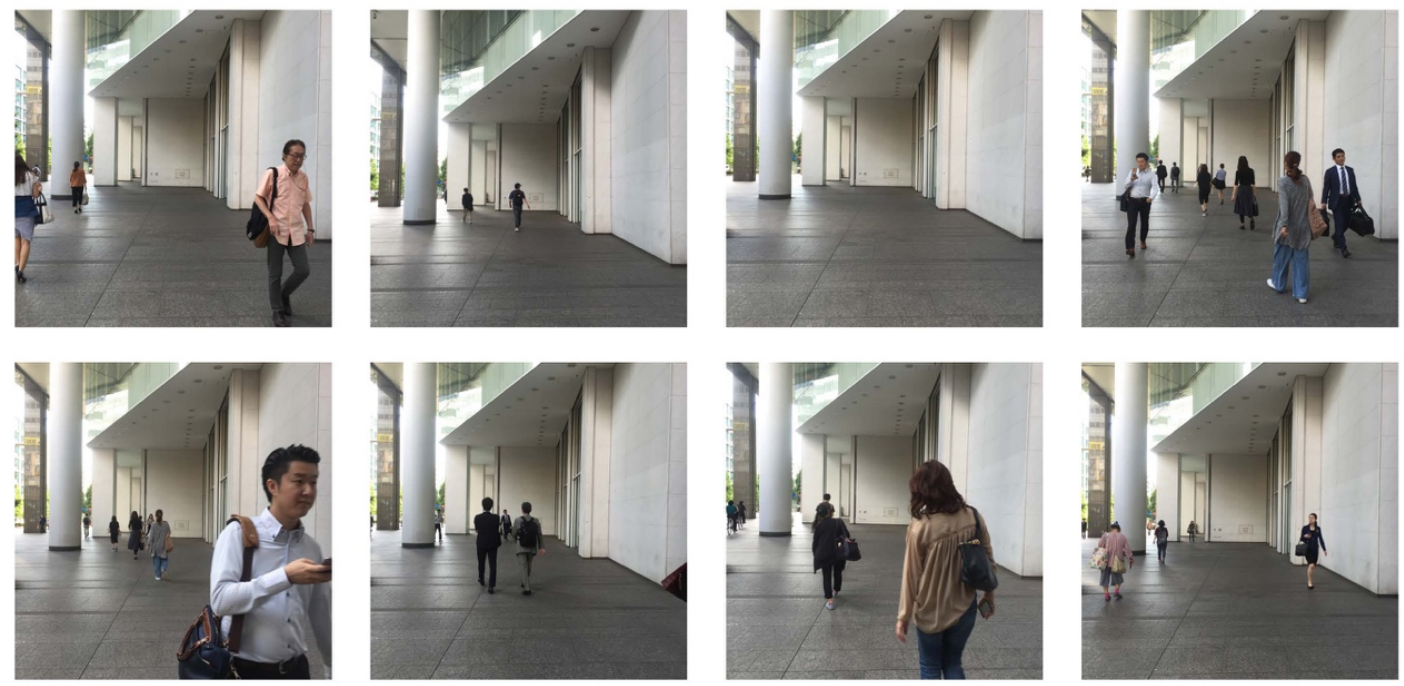

Fig. I-8. Example A, arcade.
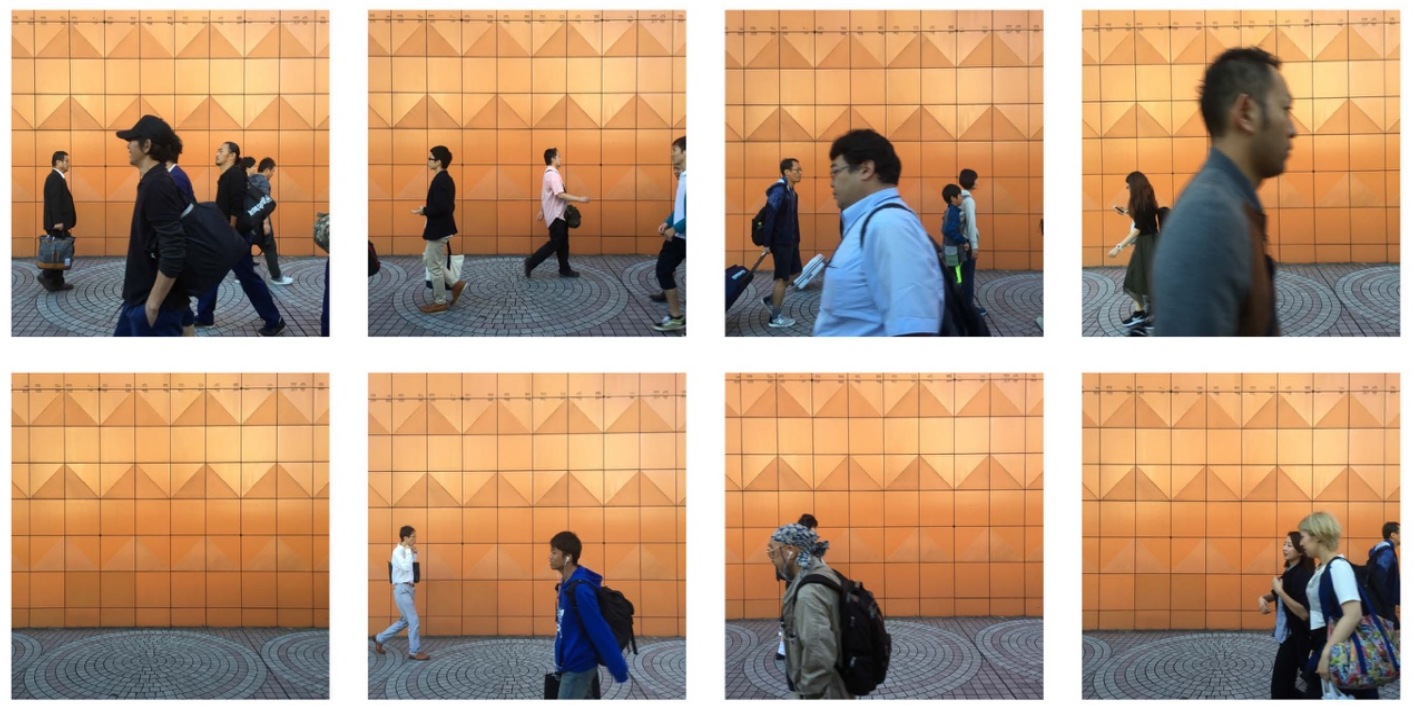

Fig. 9-16. Example B, street. 

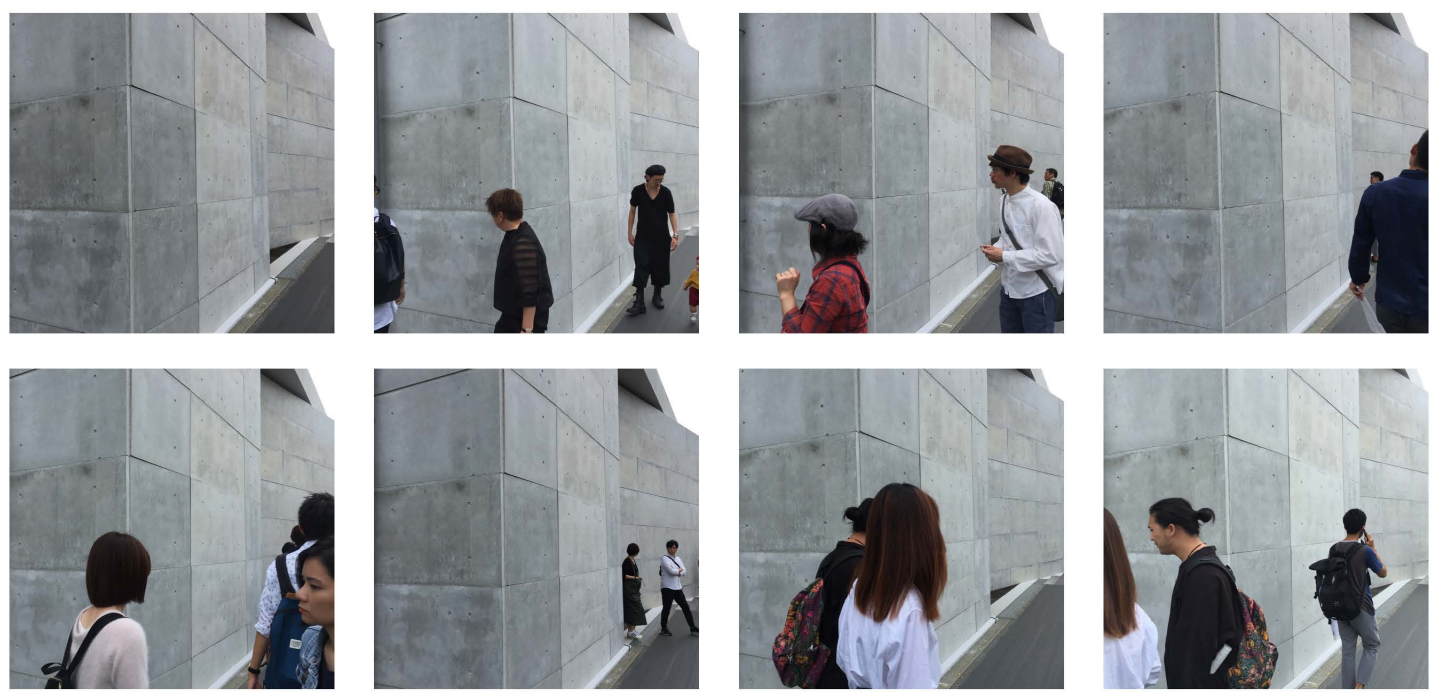

Fig. I 7-24. Example C, church.
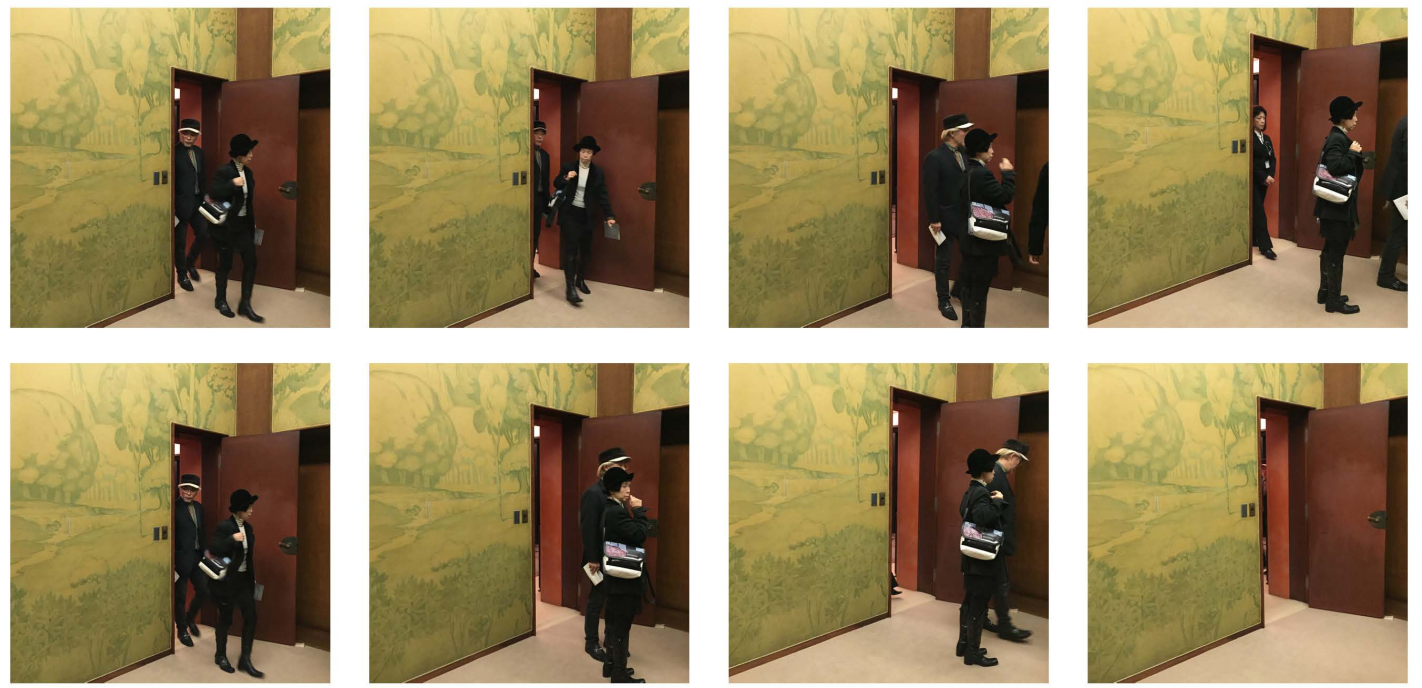

Fig. 25-32. Example D, museum.

In addition, when the number of people increases and move closer to the point of the observer, the built structure remains strong and dominant. In example $\mathrm{D}$, also based on a strong sensory and corporeal structure, the composition and movements of the dressed bodies appear in contrast to rather than elevated by the structure. The structure which is at first strong and clear, almost solitary in its form and materiality, seems immediately to give way for the interaction with a single dressed body, or even half-dressed body. This process also appears to continue to the point where not only the dressed bodies but the dress itself takes over and dominates the dynamics of the space. As the dress gets abstracted from the body however it is evident in some of the instances that it is no longer a faceless body. When one or several particular "dresses" open up their faces and glance at the observer, the dynamics of the space is changed yet again, and the bodiless dress with a face takes over the space. 


\section{Conclusions: congregations and constructions}

The aim of this pilot study was to develop a method of artistically analysing the aesthetic construction of public spaces by focusing on the interaction between dressed bodies and built constructions from a first-person perspective. The examples demonstrate that the dressed bodies have a significant impact on the aesthetics of the space as perceived by the observer and occupant of the space. Conversely the degree and type of the impact - in the sense of cultural meanings or functionalities-are more complex to determine. However, the more fundamental aesthetic qualities of the space as an a priori structure for meaning-making and other particular social functions and expressions are made evident. Moreover, in the example a primary dynamic sensory experience is at play that dominates the composition and perception of the space as the dressed bodies interact with the built structures.

The need to consider dress and dressed bodies in the understanding of public space is apparent. Not only does it confirm the notion that dressed bodies are overlooked in their interaction with built environments in challenging and co-constructing public spaces - habitat and occupational patterns - it rather suggests that dressed bodies may be the starting point for designing public space. The result demonstrates further that methods should be developed to help design spaces from the notion of dressed bodies before any activity is considered. Finally, the result suggests theories of fashion dealing with the dressed body be considered and connected to theories of public space and urban environments to encourage more dynamic conceptions and more dynamic possibilities of space.

Several limitations exist in any pilot study. Although certain dynamics and ambivalence arising between the forces of the dressed bodies and the built structures could be identified, they remain perhaps more suggestive than rigorous because of the small number of examples, limited number of people, or similarly, first-person perspectives. Moreover, while the structure of the particular photographic approach in this study, such as perspective, framing, lens angle and the clustering of the images, may on the one hand be required for the photographs to be effective in a visual cluster analysis, on the other hand, different ways of photographing may be developed for a more complex dynamic analyses of different variables in the relationship between dressed bodies and built environments in the co-creation of public space. Similarly, while one method of photography may be appropriated for a particular issue related to a particular constructed public space, different methods of photographic analysis may need to be explored to appropriately analyse different modes of dressing and building that together co-create public or semi-public space aesthetics. Thus, although the methods have been proven valuable for one form of aesthetic analysis of the co-creation of public space by dressed bodies and built environments, further development of the method is suggested. 


\section{References}

Barnard, M. (2002). Fashion as Communication. London: Routledge.

Baudrillard, J. (1983). Simulations. New York: Semiotext(e).

Baudrillard, J. (1998). The Consumer Society: Myths and Structures. London: Sage.

Benjamin, W. (2002). The Arcades Project. Cambridge: Harvard University Press.

Benjamin, W. (2007). Theses on the Philosophy of History. In H. Arendt (Ed.) Illuminations (pp. 253264). New York City: Schocken Books.

Bourriaud, N. (2002). Relational aesthetics. Paris: La presses du reel.

Carr, S., Francis, M., Rivlin, L. \& Stone, A. (1992). Public Space. Cambridge: Cambridge University Press.

Deleuze, G. (2004). Difference and Repetition. London: Continuum.

Dodds, G. \& Tavenor, D. (2002). Body and Building. Essays on the Changing Relation of Body and Architecture. Cambridge, Mass.: MIT Press.

Entwistle, J. (2000). Fashion and the Fleshy Body: Dress as Embodied Practice. Fashion Theory: The Journal of Dress, Body and Culture, 4(3): 323-348.

Evangelidis, B. (2018). Space and Time as Relations: The Theoretical Approach of Leibniz. Philosophies, 3(2), 9-0.

Farías, I. (2009). Decentring the Object of Urban Studies. In T. Bender \& I. Farías (Eds), Urban Assemblages: How Actor-Network Theory Changes Urban Studies (pp. I-24). Abingdon, UK: Routledge.

Foucault, M. (1976). The Archaeology of Knowledge. New York: Harper \& Row.

Gehl, J. (20I0). Cities for People. Washington, DC: Island Press.

Grosz, E. (200I). Architecture from the Outside. Cambridge: MIT Press.

Hegel, G. (1949). The phenomenology of mind. London: Allen \& Unwin.

Hodge, B., Mears, P., \& Sidlauskas, S. (2006). Skin and Bones: Parallel Practices in Fashion and Architecture. New York: Thames \& Hudson.

Humphreys, L. (2010). Mobile social networks and urban public space. New Media \& Society, I2(5), 763-778.

Koolhaas, R., Cha, T-W. \& Chung, C. (2001). Harvard Design School guide to shopping. Köln: Taschen.

Lange, S. (2006). Bernd and Hilla Becher: life and work. Cambridge: MIT Press.

Latour, B. (2005). Reassembling the social: An introduction to actor-network-theory. Oxford University Press.

Leach, N. (2006) Camouflage. Cambridge: MIT Press.

Lipovetsky, G. (1994). The Empire of Fashion: Dressing Modern Democracy, New Jersey: Princeton University Press.

Kenniff, T. B. (2018). Dialogue, ambivalence, public space. The Journal of Public Space, 3(I): I3-30. 
Loppa, L. (2003). Modemuseum Patronen: Patterns. Antwerp: Ludion.

Leibniz, G. W. (2000). G. W. Leibniz and Samuel Clarke: Correspondence. Indianapolis, Indiana; Hackett.

Leibniz, G. W. (2006). Discourse on Metaphysics and the Monadology. London: Dover.

Lefebvre, H. (199I). The Production of Space. Oxford, UK: Basil Blackwell.

Lefebvre H. (2003). The urban revolution. University of Minnesota Press, Minneapolis, London.

Lofland, L. H. (1998). The Public Realm: Exploring the City's Quintessential Social Territory. New York: Aldine de Gruyter.

Morton, P. (2000). Hybrid Modernities. Cambridge: MIT Press.

Oldenburg, R. (1991). The Great Good Place: Cafes, Coffee Shops, Community Centers, Beauty Parlors, General Stores, Bars, Hangouts and How They Get You Through the Day. New York: Paragon House.

Preiser, F.E., Hardy, A. E. \& Wilhelm, J. J. (2017). Adaptive Architecture: Changing Parameters and Practice London: Taylor \& Francis.

Rajagopalan, M. (2012). Preservation and Modernity: Competing Perspectives, Contested Histories and the Question of Authenticity. In. G. Crysler, S. Cairns \& H. Heynen. The SAGE handbook of architectural theory (pp. 309-324). London: SAGE.

Reinhardt, D. (2007). Elastic Space: Latent Formations in Fashion and Architecture. Architectural Theory Review, 12(2), 181-194.

Rovine, V. (2009). Colonialism's Clothing: Africa, France, and the Deployment of Fashion. Design Issues, 25(3), 44-6I.

Sabatino, M. (2008). The primitive in modern architecture and urbanism. The Journal of Architecture, 13 (4): 355-364.

Semper, G. (1989). The Four Elements of Architecture. Cambridge: Cambridge University Press.

Simmel, G. (191I). Philosophische Kultur: Gesammelte Essais. Leipzig.

Stimson, B. (2004). The Photographic Comportment of Bernd and Hilla Becher.

http://www.tate.org.uk/research/tateresearch/tatepapers/04spring/stimson_paper.htm [2012-0120]

Versluis, A. and Uyttenbroek, E. (20I4). Exactitudes Expanded with 10 New Series. Rotterdam: NAl.

Wenders, W. (1989). [DVD] Notebook on Cities and Clothes. Road Movie Filmproduction/Centre national D'art et de Culture Georges Pompidou.

Wiberg, M. (2018). The Materiality of Interaction. Notes on the Materials of Interaction Design. Cambridge: MIT Press.

Wood. J, Kamps. T., \& Harrison, P. (20II). John Wood and Paul Harrison: Answers to Questions. Houston: Contemporary Art Museum.

Zukin, S. (1995). The Cultures of Cities. Cambridge, MA: Blackwell Press.

I4 | The Journal of Public Space, 4(I), 2019 | ISSN 2206-9658

City Space Architecture / UN-Habitat 